\title{
HIV Associated Chronic Obstructive Pulmonary Disease in Nigeria
}

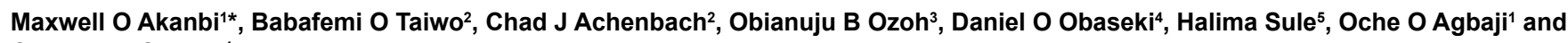

\section{Christiana O Ukoli ${ }^{1}$}

${ }^{1}$ Department of Medicine, Jos University Teaching Hospital, Jos, Nigeria

${ }^{2}$ Northwestern University Chicago, USA

${ }^{3}$ Department of Medicine, College of Medicine, University of Lagos, Lagos, Nigeria

${ }^{4}$ Department of Medicine, Obafemi Awolowo University, Ile-Ife, Nigeria

${ }^{5}$ Department of Family Medicine, Jos University Teaching Hospital, Nigeria

\begin{abstract}
Objective: To determine the prevalence and risk factors for chronic obstructive pulmonary disease (COPD) among HIV-infected adults in Nigeria.

Design: Cross-sectional study.

Methods: HIV-infected adults aged $\geq 30$ years with no acute ailments accessing care at the antiretroviral therapy clinic of Jos University Teaching Hospital were enrolled consecutively. Participants were interviewed to obtain pertinent demographic and clinical information, including exposure to risk factors for COPD. Post-bronchodilator spirometry was carried out. HIV related information was retrieved from the clinic medical records. COPD case-definition was based on the Global Initiative for Obstructive Lung Disease (GOLD) criteria using post-bronchodilator $\mathrm{FEV}_{1} / \mathrm{FVC}<0.7$. COPD prevalence was also calculated using the lower limit of normal for $F_{E V} / F V C$ criteria (LLN) from the European Respiratory Society normative equation. Factors associated with COPD were determined using logistic regression models

Results: Study population comprised 356 HIV infected adults with mean age of 44.5 (standard deviation, 7.1) years and $59 \%$ were female. The mean time elapsed since HIV diagnosis was 7.0 (SD, 2.6) years and $97.5 \%$ of the respondents were on stable ART with virologic suppression present in $67.2 \%$. Prevalence of COPD were $15.4 \%(95 \%$ confidence interval [Cl] 11.7-19.2), $12.07 \%$ (95\% Cl 8.67-15.48), 22.19\% (95\% Cl 18.16-26.83) using GOLD, ERS LLN and GLI LLN diagnostic criteria respectively. In multivariate analyses adjusting for gender, exposure to cigarette smoke or biomass, history of pulmonary tuberculosis, use of antiretroviral therapy, current CD4 T-cell count and HIV RNA, only age $>50$ years was independently associated with COPD with OR 3.4; 95\% Cl 1.42-8.17 when compared to ages 30-40 years.
\end{abstract}

Conclusion: HIV-associated COPD is common in our population of HIV patients.

Keywords: COPD; Lung disease; Spirometry; HIV; Nigeria; Africa

\section{Introduction}

Widespread access to effective antiretroviral therapy (ART) has led to increased survival in persons living with the human immunodeficiency virus (HIV) $[1,2]$. In several parts of the world, non-communicable diseases (NCDs) have replaced AIDS as the leading causes of morbidity and mortality in HIV patients, a trend that is accentuated by aging of the HIV population [3,4]. Chronic Obstructive Pulmonary Disease (COPD), the $3^{\text {rd }}$ leading cause of death worldwide, is emerging as an important NCD in the HIV population $[5,6]$.

The Pulmonary Complications of HIV Infection Study (PCHIS) was the first to describe abnormal pulmonary function tests among HIVinfected persons [7]. Subsequent studies have confirmed an increased risk of COPD in persons infected with HIV, with most reporting a higher prevalence in the ART era $[6,8,9]$. The pathogenic mechanism(s) of HIV-associated COPD remains unclear, but known COPD risk factors prevalent among persons with HIV include low economic status $[10]$ and cigarette smoking $[6,11,12]$. Irrespective of these known risk factors, HIV infection is being considered as an independent risk factor for COPD $[13,14]$.

There is little known about HIV-associated COPD in sub-Saharan Africa (SSA) where over two-thirds of HIV infected persons worldwide reside $[15,16]$. Of note, peculiarities of the HIV epidemic in SSA such as limited access to ART and overrepresentation of females and the young age group may cause the epidemiology of HIV-associated COPD to vary from that in other parts of the world. Epidemiologic variation of risk factors for COPD and possibly host genetics may influence the COPD burden in various settings. Therefore, our primary aim was to determine the prevalence of COPD diagnosed by post-bronchodilator spirometry [17], among an adult population of HIV infected persons in Nigeria. We also sought to identify factors associated with COPD in the patient population.

\section{Methods}

\section{Study settings and participants}

Between April 2013 and March 2014, consecutive adult HIV patients presenting for routine care at the Jos University Teaching Hospital (JUTH) Antiretroviral Clinic were invited to participate in this cross-sectional study. The JUTH HIV clinic is supported by the AIDS

*Corresponding author: Maxwell O Akanbi, Department of Medicine, Jos University Teaching Hospital Jos, Plateau State, Nigeria, Tel: 002348033466771; E-mail: Maxwell_akanbi@yahoo.com

Received March 18, 2015; Accepted April 27, 2015; Published May 05, 2015

Citation: Akanbi MO, Taiwo BO, Achenbach CJ, Ozoh OB, Obaseki DO, et al. (2015) HIV Associated Chronic Obstructive Pulmonary Disease in Nigeria. J AIDS Clin Res 6: 453. doi:10.4172/2155-6113.1000453

Copyright: (c) 2015 Akanbi MO, et al. This is an open-access article distributed under the terms of the Creative Commons Attribution License, which permits unrestricted use, distribution, and reproduction in any medium, provided the original author and source are credited. 
Prevention Initiative in Nigeria (APIN)/PEPFAR. It has approximately 14,000 patients as previously described [18]. Routine care at the JUTH clinic includes free antiretroviral drugs for eligible patients, CD4 count measurement every 6 months and HIV RNA quantification (viral load) yearly. The JUTH Research Ethics Committee approved the study protocol.

Patients aged 30 years or older who gave informed written consent were eligible. We selected an age cut-off of 30 years because previous studies have suggested an earlier onset of COPD in HIV-infected persons [19]. Exclusion criteria were presence of an acute illness within the 30 days preceding the study, contraindications to spirometry such as chest, abdominal or eye surgery within 3 months of the study or advanced cardio-pulmonary disease. Patients who initiated ART prior to presentation for care at the JUTH HIV clinic were excluded because we could to access or verify information such as date of first HIV positive test, nadir CD4 count or pre-treatment HIV RNA levels.

\section{Data collection}

Each participant was interviewed to obtain socio-demographic data, current respiratory symptoms, exposure to known COPD risk factors (cigarette smoking, biomass exposure, and occupational pulmonary toxins) and prior pulmonary diagnosis. Respiratory symptoms of interest were cough, phlegm production, dyspnea and wheezing. Date of first positive HIV test, ART use history, treatment for pulmonary tuberculosis, CD4 T-cell counts (nadir and current) and HIV RNA levels (pretreatment and current) were extracted from the clinic electronic database.

\section{Spirometry}

The weight and height of each participant was obtained using a stadiometer, following which spirometry was carried out by a trained technician with the patient sitting, in accordance with the protocol developed by the American Thoracic Society [20,21]. Spirometry was performed approximately 20 minutes after administration of $200 \mathrm{ug}$ of inhaled albuterol via a spacer. Spirometric measures of interest were Forced Vital Capacity (FVC) and Forced Expiratory Volume in the first second $\left(\mathrm{FEV}_{1)}\right.$. The highest value of the $\mathrm{FEV}_{1}$ and $\mathrm{FVC}_{1}$ out of three acceptable readings for each participant was taken as the representative reading and was used for analyses [20]. Spirometry was performed using the NDD EasyOne ${ }^{\mathrm{TM}}$ spirometer (ndd Medical, Zurich, Switzerland). The spirometer was set to automatically generate reports based on the ATS/ERS 2005 spirometry standard as well as predictive reference values using the European Respiratory Society (ERS) equation using the reference for "blacks" [22]. Irrespective of the automated reporting, each spirometry reading was verified for acceptability and validity by a consultant pulmonologist (Akanbi M) using the ATS/ERS criteria [20]. The spirometer was calibrated at the beginning of the study and weekly biological control tests were carried out throughout the study period.

\section{Definitions}

From self-reported interviews, patients were classified as current cigarette smokers, ex-smokers and non-smokers based on National Health Interview Survey definitions [23]. Cigarette smokers were defined as patients who reported smoking $\geq 100$ cigarettes in their lifetime. Current smokers were defined as patients who reported smoking $\geq 100$ cigarettes in their lifetime, and currently smoking every day or some days. Ex-smokers were defined as patients who reported smoking $\geq 100$ cigarettes in their lifetime but currently did not smoke. Cumulative exposure to cigarette smoking was calculated using packyears. This was determined by multiplying the average number of cigarette sticks smoked per day by the number of years the person had smoked and dividing the result by 20 .

Exposure to biomass was also determined using self-report. Persons who reported exposure to smoke from combustion of firewood, sawdust, cow-dung or corn-cubs (for cooking or room heating) on most days for more 6 months were considered to have high-level biomass exposure. This estimate was based on our clinical judgment. Similarly, persons who had exposure to dust or fumes on most days for more than 6 months were considered to have high level of exposure.

Estimated minimum duration of HIV infection was defined as the time between the first positive HIV test result and date of interview. We considered recent CD4 $\mathrm{T}$ cell count as that within three months of interview date and HIV RNA level to be those within a year of the study visit. HIV RNA was reported as undetectable if the level was $<20$ copies/ml (limit of detection of the PCR machine at the JUTH APIN laboratory).

\section{Data analysis}

The primary outcome measure was COPD defined as postbronchodilator $\mathrm{FEV}_{1} / \mathrm{FVC}<0.7$; based on the Global Initiative for Obstructive Lung Disease (GOLD) criteria [24]. Due to disagreements over the most appropriate diagnosis of COPD, we also determined overall COPD prevalence using $\mathrm{FEV}_{1} / \mathrm{FVC}$ ratio below the $5^{\text {th }}$ percentile [lower limit of normal (LLN)] after adjusting for age, height, gender and race generated using the ERS equation [22] and Global Lung Function Initiative (GLI) normative equation [25]; but this definitions were not used for subsequent analysis.

Characteristics of patients with and without COPD were compared using chi square test for categorical variables and students t-test for continuous variables. Factors associated with COPD were determined using logistic regression models. Where there was an interaction between two factors e.g. ever smoked and pack-years, the factor with the stronger association in the univariate model was used for subsequent analysis. Factors with a p-value $<0.2$ in the univariate model were included in the multivariate model to identify those independently associated with COPD. Variables previously associated with COPD were also included in the multivariate model. A backward elimination approach was then used to determine the final model; with variables with a $p$-value $<0.05$ considered significant and retained in the final model.

Statistical analyses were performed using SPSS version 19.0 (Chicago, IL) and Stata version 11 (College Station, TX).

\section{Results}

\section{Patient characteristics}

We enrolled all 500 patients who met study criteria and gave consent to participate. Data from 144 patients were excluded; 118 (23.6\%) because their spirometry did not meet the minimum ATS/ ERS criteria [20,26,27] and $26(5.2 \%)$ whose CD4 and/ or viral load results could not be traced. There were no significant differences in age or sex distribution between persons excluded and those included in the subsequent analysis ( $\mathrm{p}=0.09$ and 0.9 , respectively).

Data of 356 HIV infected adults were utilized for subsequent analysis. The mean (standard deviation) age of this population was 44.5 [Standard deviation (SD) 7.1] years, and 210 (59\%) were female. Three hundred and eighteen (89.3\%) had some formal education, and 158 (44.4\%) had tertiary education. Sixty one patients (17.1\%; all males) 


\begin{tabular}{|c|c|}
\hline Characteristic & $\begin{array}{c}\text { Entire cohort } 356 \\
\text { N (\%) }\end{array}$ \\
\hline Age, mean years, (SD) & $44.5(7.1)$ \\
\hline \multicolumn{2}{|l|}{ Age Group (Years) } \\
\hline $30-39$ & $96(27.0)$ \\
\hline $40-49$ & $179(50.2)$ \\
\hline$\geq 50$ & $81(22.8)$ \\
\hline \multicolumn{2}{|l|}{ Sex, n (\%) } \\
\hline Female & $210(59)$ \\
\hline Male & $146(41)$ \\
\hline Ever smoked, n (\%) & $61(17.1)$ \\
\hline Biomass exposure, $\mathrm{n}(\%)$ & $135(37.9)$ \\
\hline History of PTB, $n(\%)$ & $82(23)$ \\
\hline Use of ART, $n(\%)$ & $346(97.8)$ \\
\hline *Baseline CD4 T-cell count, median cells/ul(IQR) & $173(29-283)$ \\
\hline *Log pre-treatment HIV Viral Load, median copies/ml (SD) & $4.5(3.4-5.1)$ \\
\hline Recent CD4 T-cell count, median cells/ul(IQR) & $487(324-682)$ \\
\hline Current HIV Viral Load, undetectable, $n$ (\%) & $250(70.2)$ \\
\hline Time elapsed since HIV diagnosis, mean years (SD) & $8(2.6)$ \\
\hline
\end{tabular}

SD: Standard Deviation; PTB: Pulmonary Tuberculosis; ART: Antiretroviral Therapy; IQR: Interquartile Range, *CD4: cell count and viral load at first presentation for HIV care

Table 1: Characteristics of HIV-infected adults screened for Chronic Obstructive Pulmonary Disease using spirometry in Jos, Nigeria (May 2013-March 2014).

\begin{tabular}{|c|c|c|c|}
\hline Characteristic & $\begin{array}{c}\text { GOLD criteria } \\
\mathrm{n}(\%)\end{array}$ & $\begin{array}{c}\text { ERS criteria } \\
\mathrm{n}(\%)\end{array}$ & $\begin{array}{c}\text { GLI } \\
\mathrm{n}(\%)\end{array}$ \\
\hline Overall & $55(15.4)$ & $43(12.1)$ & $179(22.2)$ \\
\hline Age, years & & & \\
\hline $30-39$ & $10(10.4)$ & $11(11.5)$ & $19(19.8)$ \\
\hline $40-49$ & $22(12.3)$ & $17(9.5)$ & $33(18.4)$ \\
\hline$\geq 50$ & $23(28.4)$ & $15(18.5)$ & $27(33.3)$ \\
\hline
\end{tabular}

GOLD: Global Initiative for Obstructive Lung Disease (Forced expiratory volume in the first second $\left[\mathrm{FEV}_{1}\right] /$ Forced Vital Capacity $[\mathrm{FVC}]<0.7$ )

ERS: European Respiratory Society 1993 normative equation $\left(\mathrm{FEV}_{1} / \mathrm{FVC}\right.$ lower than the $5^{\text {th }}$ percentile)

GLI: Global Lung Initiative (2012) normative equation (FEV/FVC lower than the $5^{\text {th }}$ percentile)

Table 2: Prevalence of Chronic Obstructive Pulmonary Disease among 356 HIVinfected adults in Jos Nigeria, May 2013-March 2014. had a history of cigarette smoking and 13 (3.7\%) were current smokers. Among cigarette smokers, the median quantity of cigarette smoked was 2.5 [interquartile range (IQR) 0.6-6.6] pack years. One hundred and thirty five patients (37.9\%) reported greater than 6 months of daily exposure to biomass (considered as significant exposure in this study). Female patients had a higher frequency of biomass exposure than males; $122(58.1 \%), 13$ (8.9\%); $\mathrm{p}<0.01)$. The main activity associated with biomass exposure was household cooking (96.95\%).

The mean time elapsed since HIV diagnosis was 7.0 (SD, 2.6) years and the $97.5 \%$ were on stable ART with virologic suppression present in $64.3 \%$ (Table 1). Two hundred and ten patients $(58.9 \%)$ were on Nevirapine based ART, 49 (13.8\%) on efavirenz based ART, and 76 $(21.3 \%)$ on protease inhibitors (lopinavir or atazanavir with ritonavir).

\section{Prevalence of and factors associated with COPD}

Utilizing the GOLD criteria, COPD was diagnosed in 55 of 356 participants (15.4\%, 95\% CI 11.67-19.22). The prevalence of COPD diagnosed using the LLN was $12.1 \%$ (95\% CI 8.67-15.48) based on the ERS normative values and $22.19 \%$ (95\% CI 18.16-26.83) based on the GLI normative equation. COPD prevalence in different age groups is shown in Table 2. Based on GOLD classification of COPD severity, 7.9\% (28), 7.3\% (26), and 0.3\% (1) had stage 1 (mild), 2 (moderate) and 3 (severe) COPD, respectively. No participant had stage 4 or very severe COPD.

COPD prevalence based on patient characteristics is shown in Table 3. In univariate analysis, odds for COPD were higher in patients older than 50 years compared to those between the ages of 30-40 years $(p<0.01)$, persons with $>20$ years of cigarette smoking compared to persons with $<1$ year of smoking $(\mathrm{p}=0.03)$ and recent CD4 count $<200$ cells $/ \mu \mathrm{l}(\mathrm{p}=0.02)$. Age $>50$ years was the only independent predictors of COPD in multivariate analysis (Table 4).

\section{Respiratory Symptoms and HIV-associated COPD}

A total of 62 patients (17.4\%) had at least one respiratory symptom. Documented respiratory symptoms were dyspnea $(n=39 ; 11.1 \%)$, cough $(n=25 ; 7.0 \%)$, phlegm production $(n=18 ; 5.1 \%)$ and wheezing $(n=16 ; 4.5 \%) .29 \%$ of persons with respiratory symptoms had COPD compared to $12.6 \%$ among asymptomatic patients $(\mathrm{p}=0.003)$. Persons

\begin{tabular}{|c|c|c|c|}
\hline Characteristic & $\begin{array}{c}\begin{array}{c}\text { COPD-free } \\
N=301\end{array}\end{array}$ & $\begin{array}{l}\text { COPD } \\
\mathrm{N}=55\end{array}$ & p-value \\
\hline Age, mean years, (SD) & $43.9(6.7)$ & $47.8(8.4)$ & $<0.01$ \\
\hline \multicolumn{4}{|l|}{ Age Group (Years), n (\%) } \\
\hline $30-39$ & $86(28.6)$ & $10(18.2)$ & $<0.01$ \\
\hline $40-49$ & $157(52.2)$ & $22(40.0)$ & \\
\hline$\geq 50$ & $58(19.3)$ & $23(41.8)$ & \\
\hline Sex, male, n (\%) & $118(39.2)$ & $28(50.9)$ & 0.11 \\
\hline Ever smoked, $\mathrm{n}(\%)$ & $48(15.9)$ & $13(23.6)$ & 0.16 \\
\hline Biomass exposure, $\mathrm{n}(\%)$ & $118(39.2)$ & $17(30.9)$ & 0.24 \\
\hline History of PTB, n (\%) & $67(22.3)$ & $15(27.3)$ & 0.42 \\
\hline Use of ART, n (\%) & $295(98)$ & $53(96.4)$ & 0.45 \\
\hline *Baseline CD4 T-cell count, Median cells/ul(IQR) & $177(82-286)$ & $154(62-272)$ & 0.12 \\
\hline *Log pre-treatment HIV RNA, mean copies/ml (SD) & $4.2(1.2)$ & $4.1(1.2)$ & 0.50 \\
\hline Recent CD4 T-cell count, median cells/ul(IQR) & $496(326-692)$ & $441(309-829)$ & 0.19 \\
\hline Recent CD4 T-cell count < 200 cells/ul, n(\%) & $25(8.4)$ & $10(18.9)$ & 0.02 \\
\hline Current HIV Viral Load, undetectable, n (\%) & $211(70.3)$ & $39(70.9)$ & 0.93 \\
\hline Time elapsed since HIV diagnosis, mean years (SD) & $7.1(2.5)$ & $6.9(2.7)$ & 0.68 \\
\hline
\end{tabular}

SD: Standard Deviation; PTB: Pulmonary Tuberculosis; ART: Antiretroviral Therapy; IQR: Interquartile Range, ${ }^{*} \mathrm{CD} 4$ : cell count and viral load at first presentation for HIV care Table 3: Characteristics of HIV-infected adults stratified by Chronic Obstructive Pulmonary Disease diagnosis in Jos, Nigeria (May 2013-March 2014). 
Citation: Akanbi MO, Taiwo BO, Achenbach CJ, Ozoh OB, Obaseki DO, et al. (2015) HIV Associated Chronic Obstructive Pulmonary Disease in Nigeria. J AIDS Clin Res 6: 453. doi:10.4172/2155-6113.1000453

Page 4 of 6

\begin{tabular}{|c|c|c|c|c|c|c|}
\hline \multirow[t]{2}{*}{ Characteristic } & \multicolumn{3}{|c|}{ Univariate Analysis } & \multicolumn{3}{|c|}{ Multivariate } \\
\hline & OR & $95 \% \mathrm{Cl}$ & $p$-value & OR & $95 \% \mathrm{Cl}$ & $p$-value \\
\hline Age, years & & & $<0.01$ & & & 0.01 \\
\hline $30-40$ & Ref. & & & Ref. & & \\
\hline$>40-50$ & 1.21 & $0.55-2.66$ & 0.64 & 1.33 & $0.57-3.14$ & 0.51 \\
\hline$>50$ & 3.41 & $1.51-7.69$ & $<0.01$ & 3.40 & $1.42-8.17$ & 0.01 \\
\hline \multicolumn{7}{|l|}{ Gender } \\
\hline Female & Ref. & & & & & \\
\hline Male & 1.61 & $0.90-2.86$ & 0.11 & - & - & - \\
\hline Duration of cigarette smoking (Years) & & & 0.09 & & & \\
\hline$<1$ & Ref & & & & & \\
\hline $1-20$ & 0.94 & $0.37-2.36$ & 0.89 & - & - & - \\
\hline$>20$ & 3.69 & $1.13-11.59$ & 0.03 & - & - & - \\
\hline Duration of biomass exposure (years) & & & 0.20 & & & \\
\hline$<1$ & Ref & & & & & \\
\hline $1-20$ & 0.91 & $0.47-1.75$ & 0.70 & - & - & - \\
\hline 20 & 1.93 & $0.88-4.22$ & 0.10 & - & - & - \\
\hline \multicolumn{7}{|l|}{ History of PTB } \\
\hline No & Ref. & & & & & \\
\hline Yes & 0.76 & $0.40-1.47$ & 0.42 & - & - & - \\
\hline \multicolumn{7}{|l|}{ On ART } \\
\hline No & Ref. & & & - & & \\
\hline Yes & 1.85 & $0.37-9.44$ & 0.46 & - & - & - \\
\hline \multicolumn{7}{|l|}{ Current CD4 T-cell count, cells/ $/ \mu \mathrm{l}$} \\
\hline$\geq 200$ & Ref & & & Ref & & 0.09 \\
\hline$<200$ & 2.53 & $1.14-5.63$ & 0.02 & 2.17 & $0.88-5.36$ & \\
\hline \multicolumn{7}{|l|}{ Current HIV Viral Load } \\
\hline Undetectable & Ref. & & & - & & \\
\hline Detectable & 0.97 & $0.52-1.83$ & 0.93 & - & - & - \\
\hline
\end{tabular}

PTB- Pulmonary Tuberculosis; ART- Antiretroviral therapy; OR-Odds ratio

Table 4: Univariate and multivariate logistic regression models of factors associated with Chronic Obstructive Pulmonary Disease among HIV-infected adults at the Jos University Teaching Hospital HIV Clinic (May 2013-March 2014)

with COPD were more likely to report wheezing (OR 4.7; 95\% CI 1.713.13, $\mathrm{p}=0.003$ ) or dyspnea (OR 3.27; 95\% CI 1.6-6.9, $\mathrm{p}=0.002$ ). We did not find a significant association between cough (OR 1.8; $95 \%$ CI 0.7 4.8, $\mathrm{p}=0.23$ ) or phlegm expectoration (OR 1.6, 95\% CI 0.5-5.1, $\mathrm{p}=0.42)$ and COPD.

\section{Previous asthma diagnosis and HIV-associated COPD}

Seven patients $(2 \%)$ had a previous diagnosis of bronchial asthma while none had a previous diagnosis of COPD. COPD prevalence among patients who reported a previous diagnosis of asthma was $57.1 \%$ compared to $14.6 \%$ in persons without a previous diagnosis of asthma $(\mathrm{p}=0.01)$.

\section{Discussion}

Despite the high burden of HIV in SSA, there is limited information on the burden of HIV-associated COPD on the continent. We determined COPD prevalence in a clinic cohort of HIV infected adults in long term care in Jos, Nigeria. Utilizing the GOLD COPD diagnostic criteria of post bronchodilator spirometry, the prevalence of COPD in our population of HIV infected adults aged 30 years and above was $14.47 \%$ with almost all of these cases (98\% of the total cases) being of mild or moderate severity. COPD prevalence was $12.1 \%$ based on the ERS LLN criteria and $22.19 \%$ based on GLI LLN criteria. We found COPD to be independently associated with older age (above 50 years compared to 30 to 40 year old). Persons with CD4 T-cell count $<200$ cells/ $\mu$ l tended to have a higher of COPD but this difference was not statistically significant $(p=0.09)$. Further, participants with COPD were more likely to report wheezing and coughing, consistent with the typical clinical features of this condition. Biomass exposure and cigarette smoking did not significantly contribute to COPD risk in our patient population, albeit our definitions of significant biomass exposure were based on expert opinion.

High COPD prevalence has been reported among patients with HIV infection; with spirometry diagnosed COPD prevalence ranging from $6.8 \%(27)$ to $21 \%$ [28]. In addition, markers of airway obstruction such as lower expiratory flow rates [29], bronchial hyper responsiveness [30] and air trapping [31] have been demonstrated in persons with HIV. With the high prevalence of HIV in SSA, COPD in the aging HIV population is likely to contribute significantly to long-term morbidity in the region. Unfortunately, awareness of COPD among physicians [32] and the general population is low in SSA and this is compounded by low availability of spirometry [33]. This implies that many patients with COPD remain undiagnosed. 
HIV-associated COPD presents unique challenges in SSA. Symptoms of COPD such as chronic cough with phlegm expectoration among persons with HIV in our setting is often attributed to infections especially tuberculosis. Since TB diagnosis is often based on smear microscopy, many patients with COPD may be erroneously diagnosed with 'smear negative' TB. Additionally, the prevalence of COPD risk factors may also vary across populations of HIV-infected persons in SSA. Cigarette smoking which is regarded as the most important risk factor for COPD globally [34], has been commonly reported in HIVinfected persons in Western Nations. In our cohort, only $17.1 \%$ of the participants ever smoked cigarettes compared to over $60 \%$ among HIVinfected persons in the U.S. and Europe [12,35]. Another important modifiable contributor to COPD burden in low- and middle-income countries (LMICs) such as Nigeria is exposure to biomass [26]. A high proportion of the women in our study (58.1\%) reported high-level exposure to biomass. Cumulative exposure to biomass is known to increase COPD risk, [36,37] and household cooking in rural setting has been shown to increase COPD in elderly women [38]. However, despite the high prevalence of exposure to biomass in our female population, it was not an independent predictor of COPD, possibly because of young age of the participants and outdoor cooking which often occurs in many rural areas in Nigeria. Notwithstanding, as our HIV population ages the cumulative exposure to biomass may become an important contributor to COPD.

Respiratory infections are common in persons with HIV and contribute to lung function impairment. Tuberculosis is one of the most common respiratory infections in Africa. A history of pulmonary tuberculosis (PTB) was present in $23.5 \%$ of the patients in our study, but an association with COPD was not detected. TB has been associated with COPD by other investigators such as Ehrlich and colleagues [39] in South Africa who found a strong association between TB and chronic bronchitis, diagnosed by the presence of chronic cough. Chronic cough and airway obstruction following TB may be due to bronchiectasis, often resulting from extensive fibrosis and destruction of airway architecture [40,41]. However, in the setting of HIV, TB is often paucibacillary, with absence of classical extensive fibrosis suggesting that other factors may contribute to the presence of airway obstruction [42]. Among opportunistic lung infections, Pneumocystis jirovecii has shown the strongest association with COPD [43], but a low prevalence of Pneumocystis jirovecii has been reported in SSA [44,45], hence its contribution to HIV associated COPD in the region remains uncertain.

HIV specific factors that have been associated with COPD risk include low CD4 T-cell count, high viral load and recurrent or chronic pulmonary infections $[6,16,27]$. In our study, COPD tended to be more common in persons with CD4 T-cell count below 200 cells $/ \mu$; the association between viral load and COPD was however weak. Our findings are similar to that documented in the Veterans Aging Cohort Study [6] in which HIV-infected persons had significantly lower CD4 $\mathrm{T}$ cell count compared to those without COPD, but with no significant differences in HIV viral load. Contrasting this is the study by Gingo et al. [28], where neither low CD4 cell count nor high viral load was associated airway obstruction. Notably, in a longitudinal study of 1064 participants with or without HIV-infection in Baltimore, USA, Drummond et al. [46] observed a more rapid decline in FEV and FVC among HIV-infected persons with viral load above 75000 copies $/ \mathrm{ml}$ compared with uninfected persons. Similarly, HIV positive persons with CD4 cell count less than 100 cells/ $\mu$ had a more rapid decline in $\mathrm{FEV}_{1}$ and FVC. Despite the findings from recent studies showing lower lung function indices in the presence of poorly controlled HIV disease, it remains unclear if this is due to direct cytopathogenic effects of the
HIV virus on the lungs or a marker of other factors such as cigarette smoking or recurrent lung infections.

Our study is one of the first to report on the burden of HIVassociated COPD in SSA, and the first to do so in Nigeria, the country with the second highest number of HIV patients in the world. Despite the low prevalence of cigarette smoking in our population and wellcontrolled HIV disease in the majority of patients in our study, we report a high prevalence of COPD, all previously undiagnosed. One of our limitations was the constrained ability to assess for risk factors for COPD due the cross-sectional study design. This and the low number of ART naïve participants limited our assessment of the impact of ART on COPD. A notable strength of our study is the use of post bronchodilator spirometry, the gold standard for COPD diagnosis. The use of GOLD criteria and LLN for COPD diagnosis improved the accuracy of our estimation of COPD burden.

In conclusion, we have demonstrated that COPD prevalence is high among HIV-infected adult Nigerians and that the risk for COPD is associated with older age. The pervasive COPD under-diagnosis demonstrated in our study is a major challenge and brings to the fore the need to train and equip HIV care providers to recognize and diagnose COPD. It is also important for policy makers to consider incorporating screening spirometry into routine HIV management practices so as to increase early diagnosis and treatment of COPD since this has the potential to improve outcomes.

\section{Acknowledgement}

The authors gratefully acknowledge Stephen Gordon, staff and patients of the JUTH HIV clinic, Jos Nigeria and the Pan African Thoracic Society for their contribution to this study.

\section{Conflict of Interest and Source of Funding}

MOA was supported through grants from the American Thoracic Society (ATS Foundation Research grant) and NIH grant R24TW008878. Other authors declare no conflict of interest. The contents of this paper are solely the responsibility of the authors and do not necessarily represent the official views of the American Thoracic Society or the NIH.

\section{References}

1. Farahani M, Vable A, Lebelonyane R, Seipone K, Anderson M, et al. (2014) Outcomes of the Botswana national HIVIAIDS treatment programme from 2002 to 2010: a longitudinal analysis. Lancet Glob Health 2: e44-50.

2. Samji H, Cescon A, Hogg RS, Modur SP, Althoff KN, et al. (2013) Closing the gap: increases in life expectancy among treated HIV-positive individuals in the United States and Canada. PLoS One 8: e81355.

3. Effros RB, Fletcher CV, Gebo K, Halter JB, Hazzard WR, et al. (2008) Aging and infectious diseases: workshop on HIV infection and aging: what is known and future research directions. Clin Infect Dis 47: 542-553.

4. Schouten J, Wit FW, Stolte IG, Kootstra NA, van der Valk M, et al. (2014) Crosssectional Comparison of the Prevalence of Age-Associated Comorbidities and Their Risk Factors Between HIV-Infected and Uninfected Individuals: The AGEhIV Cohort Study. Clin Infect Dis 59: 1787-1797.

5. Lozano R, Naghavi M, Foreman K, Lim S, Shibuya K, et al. (2012) Global and regional mortality from 235 causes of death for 20 age groups in 1990 and 2010: a systematic analysis for the Global Burden of Disease Study 2010. Lancet 380: 2095-2128.

6. Crothers K, Butt AA, Gibert CL, Rodriguez-Barradas MC, Crystal S, et al. (2006) Increased COPD among HIV-positive compared to HIV-negative veterans. Chest 130: 1326-1333.

7. Rosen MJ, Lou Y, Kvale PA, Rao AV, Jordan MC, et al. (1995) Pulmonary function tests in HIV-infected patients without AIDS. Pulmonary Complications of HIV Infection Study Group. Am J Respir Crit Care Med 152: 738-745.

8. Petrache I, Diab K, Knox KS, Twigg HL 3rd, Stephens RS, et al. (2008) HIV associated pulmonary emphysema: a review of the literature and inquiry into its mechanism. Thorax 63: 463-469. 
Citation: Akanbi MO, Taiwo BO, Achenbach CJ, Ozoh OB, Obaseki DO, et al. (2015) HIV Associated Chronic Obstructive Pulmonary Disease in Nigeria. J AIDS Clin Res 6: 453. doi:10.4172/2155-6113.1000453

9. Hull MW, Phillips P, Montaner JS (2008) Changing global epidemiology of pulmonary manifestations of HIVIAIDS. Chest 134: 1287-1298.

10. Prescott E, Lange P, Vestbo J (1999) Socioeconomic status, lung function and admission to hospital for COPD: results from the Copenhagen City Heart Study. Eur Respir J 13: 1109-1114.

11. Viegi G, Paoletti P, Prediletto R, Carrozzi L, Fazzi P, et al. (1988) Prevalence of respiratory symptoms in an unpolluted area of northern Italy. Eur Respir $\mathrm{J}$ 1: $311-318$.

12. Bénard A, Tessier JF, Rambeloarisoa J, Bonnet F, Fossoux H, et al. (2006) HIV infection and tobacco smoking behaviour: prospects for prevention? ANRS CO3 Aquitaine Cohort, 2002. Int J Tuberc Lung Dis 10: 378-383.

13. Yearsley MM, Diaz PT, Knoell D, Nuovo GJ (2005) Correlation of HIV-1 detection and histology in AIDS-associated emphysema. Diagn Mol Pathol 14: 48-52.

14. Crothers K, Huang L, Goulet JL, Goetz MB, Brown ST, et al. (2011) HIV infection and risk for incident pulmonary diseases in the combination antiretroviral therapy era. Am J Respir Crit Care Med 183: 388-395.

15. WHO, UNAIDS, UNICEF (20111) Progress report 2011: Global HIVIAIDS response. Epidemic update and health sector progress towards universal access.

16. Raynaud C, Roche N, Chouaid C (2011) Interactions between HIV infection and chronic obstructive pulmonary disease: Clinical and epidemiological aspects. Respir Res 12: 117.

17. [No authors listed] (1995) Standards for the diagnosis and care of patients with chronic obstructive pulmonary disease. American Thoracic Society. Am J Respir Crit Care Med 152: S77-121

18. Akanbi MO, Achenbach CJ, Feinglass J, Taiwo B, Onu A, et al. (2013) Tuberculosis after one year of combination antiretroviral therapy in Nigeria: a retrospective cohort study. AIDS Res Hum Retroviruses 29: 931-937.

19. Diaz PT, Clanton TL, Pacht ER (1992) Emphysema-like pulmonary disease associated with human immunodeficiency virus infection. Ann Intern Med 116: 124-128.

20. Miller MR, Hankinson J, Brusasco V, Burgos F, Casaburi R, et al. (2005) Standardisation of spirometry. Eur Respir J 26: 319-338.

21. Pellegrino R, Viegi G, Brusasco V, Crapo RO, Burgos F, et al. (2005) Interpretative strategies for lung function tests. Eur Respir J 26: 948-968.

22. Quanjer PH, Tammeling GJ, Cotes JE, Pedersen OF, Peslin R, et al. (1993) Lung volumes and forced ventilatory flows. Report Working Party Standardization of Lung Function Tests, European Community for Steel and Coal. Official Statement of the European Respiratory Society. Eur Respir J Suppl 16: 5-40.

23. Centers for Disease Control and Prevention (CDC) (2005) Cigarette smoking among adults--United States, 2004. MMWR Morb Mortal Wkly Rep 54: 11211124.

24. Vestbo J, Hurd SS, Agustí AG, Jones PW, Vogelmeier C, et al. (2013) Global strategy for the diagnosis, management, and prevention of chronic obstructive pulmonary disease: GOLD executive summary. Am J Respir Crit Care Med 187: 347-365.

25. Quanjer PH, Stanojevic S, Cole TJ, Baur X, Hall GL, et al. (2012) Multi-ethnic reference values for spirometry for the 3-95-yr age range: the global lung function 2012 equations. Eur Respir J 40: 1324-1343.

26. Lopez AD, Shibuya K, Rao C, Mathers CD, Hansell AL, et al. (2006) Chronic obstructive pulmonary disease: current burden and future projections. Eur Respir J 27: 397-412.

27. George MP, Kannass M, Huang L, Sciurba FC, Morris A (2009) Respiratory symptoms and airway obstruction in HIV-infected subjects in the HAART era. PLoS One 4: e6328.

28. Gingo MR, George MP, Kessinger CJ, Lucht L, Rissler B, et al. (2010) Pulmonary function abnormalities in HIV-infected patients during the current antiretroviral therapy era. Am J Respir Crit Care Med 182: 790-796.

29. O'Donnell CR, Bader MB, Zibrak JD, Jensen WA, Rose RM (1988) Abnorma airway function in individuals with the acquired immunodeficiency syndrome. Chest 94: 945-948.

30. Poirier CD, Inhaber N, Lalonde RG, Ernst P (2001) Prevalence of bronchial hyperresponsiveness among HIV-infected men. Am J Respir Crit Care Med 164: 542-545.
31. Gelman M, King MA, Neal DE, Pacht ER, Clanton TL, et al. (1999) Foca air trapping in patients with HIV infection: CT evaluation and correlation with pulmonary function test results. AJR Am J Roentgenol 172: 1033-1038.

32. Ozoh OB, Awokola BI, Buist SA (2014) A survey of the knowledge of genera practitioners, family physicians and pulmonologists in Nigeria regarding the diagnosis and treatment of chronic obstructive pulmonary disease. West Afr J Med 33: 100-106.

33. Mehrotra A, Oluwole AM, Gordon SB (2009) The burden of COPD in Africa: a literature review and prospective survey of the availability of spirometry for COPD diagnosis in Africa. Trop Med Int Health 14: 840-848.

34. Mannino DM, Buist AS (2007) Global burden of COPD: risk factors, prevalence, and future trends. Lancet 370: 765-773.

35. Gritz ER, Vidrine DJ, Lazev AB, Amick BC 3rd, Arduino RC (2004) Smoking behavior in a low-income multiethnic HIVIAIDS population. Nicotine Tob Res 6: 71-77.

36. Orozco-Levi M, Garcia-Aymerich J, Villar J, Ramírez-Sarmiento A, Antó JM, et al. (2006) Wood smoke exposure and risk of chronic obstructive pulmonary disease. Eur Respir J 27: 542-546.

37. Lou P, Zhu Y, Chen P, Zhang P, Yu J, et al. (2012) Vulnerability of patients with chronic obstructive pulmonary disease according to gender in China. Int $J$ Chron Obstruct Pulmon Dis 7: 825-832.

38. Hu G, Zhou Y, Tian J, Yao W, Li J, et al. (2010) Risk of COPD from exposure to biomass smoke: a metaanalysis. Chest 138: 20-31.

39. Ehrlich RI, White N, Norman R, Laubscher R, Steyn K, et al. (2004) Predictors of chronic bronchitis in South African adults. Int J Tuberc Lung Dis 8: 369-376

40. Jordan TS, Spencer EM, Davies P (2010) Tuberculosis, bronchiectasis and chronic airflow obstruction. Respirology 15: 623-628.

41. Bhatta N, Dhakal SS, Rizal S, Kralingen KW, Niessen L (2008) Clinical spectrum of patients presenting with bronchiectasis in Nepal: evidence of linkage between tuberculosis, tobacco smoking and toxic exposure to biomass smoke. Kathmandu Univ Med J (KUMJ) 6: 195-203.

42. Elliott AM, Namaambo K, Allen BW, Luo N, Hayes RJ, et al. (1993) Negative sputum smear results in HIV-positive patients with pulmonary tuberculosis in Lusaka, Zambia. Tuber Lung Dis 74: 191-194.

43. Sivam S, Sciurba FC, Lucht LA, Zhang Y, Duncan SR, et al. (2011) Distribution of Pneumocystis jirovecii in lungs from colonized COPD patients. Diagn Microbiol Infect Dis 71: 24-28.

44. Mahomed AG, Murray J, Klempman S, Richards G, Feldman C, et al. (1999) Pneumocystis carinii pneumonia in HIV infected patients from South Africa. East Afr Med J 76: 80-84

45. Carme B, Mboussa J, Andzin M, Mbouni E, Mpele P, et al. (1991) Pneumocystis carinii is rare in AIDS in Central Africa. Trans R Soc Trop Med Hyg 85: 80

46. Drummond MB, Merlo CA, Astemborski J, Kalmin MM, Kisalu A, et al. (2013) The effect of HIV infection on longitudinal lung function decline among IDUs: a prospective cohort. AIDS 27: 1303-1311. 